\title{
Jornalismo transmídia e produção de sentidos para o cinema: o filme Vingadores - guerra infinita nos portais de notícias brasileiros
}

\section{Transmedia journalism and meaning production for the cinema: the film Avengers - Infinite War on Brasilian News Portals}

\section{Periodismo transmedia y producción de significado para el cine: la película Avengers - Infinite War on Brasilian News Portals}

\author{
João Marcos Mainardes de Paula \\ Universidade do Vale do Itajaí - UNIVALI - Brasil \\ E-mail: jmmdepaula@gmail.com
}

\author{
Rafael José Bona \\ Fundação Universidade Regional de Blumenau - FURB - Brasil \\ Universidade do Vale do Itajaí - UNIVALI - Brasil \\ ORCID: https://orcid.org/0000-0003-2116-2407 \\ Endereço currículo Plataforma Lattes: http://lattes.cnpq.br/4474574048534791 \\ E-mail: bona.professor@gmail.com
}

Resumo: O objetivo do artigo é o de analisar a narrativa transmídia jornalística do filme Vingadores: guerra infinita (2018, Anthony e Joe Russo) nos portais de notícias brasileiros. Esta pesquisa se classifica como descritiva, com abordagem qualitativa e utiliza a técnica de análise de conteúdo. Foram selecionados como amostra, para análise, notícias publicadas em cada um dos seguintes portais: G1, Globoplay e Omelete entre dezembro de 2017 e setembro de 2018. Como principal resultado constatou-se que os referidos portais de notícias brasileiros, cada um com suas peculiaridades, dão novos sentidos para o filme e assim, contribuem para uma narrativa transmídia.

Palavras-chave: Jornalismo. Transmídia. Cinema. Vingadores. Brasil.

Abstract: The purpose of this article is to analyze the journalistic transmedia storytelling of the movie Avengers: infinite war (2018, Anthony and Joe Russo) in Brazilian news websites. This research is classified as descriptive, with a qualitative approach and uses the technique of content analysis. To the analysis we selected news published in each of the following websites: G1, Globoplay and Omelete between December 2017 and September 2018. As the main result it was verified that those Brazilian websites, with their own peculiarities, give new meanings to the film and thus contribute to a transmedia storytelling.

Keywords: Journalism. Transmedia. Movie theater. Avengers. Brazil. 
Jornalismo transmídia e produção de sentidos para o cinema:

o filme Vingadores - guerra infinita nos portais de notícias brasileiros

PAULA, BONA, 2019

Resumen: El objetivo del artículo es analizar la narrativa transmedia periodística de la película Vengadores: infinite war (2018, Anthony y Joe Russo) en los portales de noticias brasileños. Esta investigación se clasifica como descriptiva, con abordaje cualitativo y utiliza la técnica de análisis de contenido. Se seleccionaron como muestra, para análisis, noticias publicadas en cada uno de los siguientes portales: G1, Globoplay y Omelete entre diciembre de 2017 y septiembre de 2018. Como principal resultado se constató que los referidos portales de noticias brasileños, cada uno con sus peculiaridades, dan nuevos sentidos para la película y así, contribuyen a una narrativa transmedia.

Palabras clave: Periodismo. Transmedia. Cine. Vengadores. Brasil.

\section{Introdução}

A narrativa transmídia amplia o campo de conteúdo apresentado, visto que, variados conteúdos são divididos em várias mídias, mas todos acabam se complementando, fazendo com que quem o consuma não tenha uma visão parcial do assunto em questão (JENKINS, 2009).

A necessidade de evolução fez com que o jornalismo usasse da narrativa transmídia por meio das tecnologias disponíveis para ampliar a imersão do espectador ou leitor. O fato de que a convergência no jornalismo é um processo natural, que interfere diretamente em aspectos mercantis, públicos e tecnológicos, guia a transmídia em um caminho compreensível para com a comunicação, seguindo o conceito de Scolari (2009), que diz que a transmídia deve ser feita com o uso de meios diferentes, como cinema, televisão etc. Entre os muitos exemplos que podem ser citados na área do Jornalismo, há as matérias relacionadas a franquias cinematográficas, como as da Marvel, que expandem o universo dos filmes para além do que é apresentado nas obras.

Vingadores: guerra infinita (2018, Anthony e Joe Russo) faz parte da franquia Os Vingadores, que pertence ao UCM (Universo Cinematográfico Marvel), liderado por Kevin Feige e iniciado no ano de 2008, com o filme Homem de Ferro, do diretor americano Jon Favreau. O UCM adapta as histórias e os personagens dos quadrinhos da Marvel, que em sua maioria foram criados por Stan Lee, Jack Kirby e Steve Ditko, durante a década de 1960. Considerando apenas Vingadores: guerra infinita, o penúltimo filme da franquia principal da Marvel, a bilheteria total foi de US\$ 
Jornalismo transmídia e produção de sentidos para o cinema:

o filme Vingadores - guerra infinita nos portais de notícias brasileiros

PAULA, BONA, 2019

2.046.664.003, sendo US\$ 678.815.482 nos Estados Unidos e US\$ 1.367.848.521 no resto do mundo (BOX OFFICE MOJO, 2018).

Em suma, o jornalismo acaba expandindo o universo do filme por meio de reportagens, entrevistas e críticas. Tal expansão é o que conecta o conteúdo com a navemãe, termo usado por Jenkins para se referir à mídia principal, no caso, o longametragem. No Brasil, portais como o G1, Globoplay e Omelete usam dos recursos da narrativa transmídia por meio de conteúdos produzidos para diversas mídias, se adequando à plataforma, além de novas produções destinadas a tal mídia, como, por exemplo, os vídeos anexados às matérias, que são produzidos à parte, se enquadrando no conceito de Santos (2017). Esses conteúdos podem ser divulgados em redes sociais, possibilitando o alcance e a circulação, conforme explicam Renó e Flores (2012).

A bilheteria e crítica constatam que Vingadores: guerra infinita foi um sucesso. No portal IMDB (2018), o longa-metragem conta com uma aprovação de 8.5/10. A nova forma de se adaptar histórias em quadrinhos criada pela Marvel Studios segue um conceito parecido com o próprio material fonte, que são histórias intercaladas, formando algo muito maior, caiu no gosto não só do público em geral, mas também no da crítica especializada, fazendo com que o gênero super-heróis ganhasse muito destaque, não apenas no cinema, mas na cultura popular em geral.

Devido ao sucesso, portais de notícias, como o G1 e o Omelete buscam por expandir as informações apresentadas nos filmes, trazendo um conteúdo que vai além do que foi mostrado. Diversas questões, teorias de fãs, entre outras coisas, são levantadas em matérias, reportagens, entrevistas com elenco, que abrangem um conteúdo extenso.

Com base nisso, a pesquisa tomará o caminho da seguinte questão norteadora: como o Jornalismo pode contribuir na produção de sentidos das franquias de cinema e, assim, ocorrer uma espécie de narrativa transmídia? De que forma o universo do filme Vingadores: guerra infinita é expandido pelo jornalismo do portal G1? Como as reportagens do Globoplay propõem uma narrativa transmídia do filme? Como as matérias do portal Omelete fazem parte de uma narrativa transmídia? A partir da exposição das questões-problema de pesquisa, apresenta-se o objetivo geral: analisar a narrativa transmídia jornalística do filme Vingadores: guerra infinita nos portais de notícias brasileiros. Os objetivos específicos são: identificar o conteúdo transmídia a partir das 
matérias do portal G1; analisar a construção da narrativa audiovisual das matérias do Globoplay; analisar a influência da narrativa transmídia nas matérias do Omelete.

\section{Revisão de literatura}

Para o desenvolvimento da pesquisa, serão citados diversos conceitos apresentados e debatidos por autores da área. Jenkins (2009) trata convergência midiática como metamorfose dos meios de comunicação para que passem a trabalhar em sintonia com outras plataformas, como a internet, além das questões de mercado e engajamento do público. Referente à narrativa transmídia, o autor argumenta sobre o uso de variadas mídias:

\footnotetext{
$\mathrm{Na}$ forma ideal de narrativa transmidiática, cada meio faz o que faz de melhor - a fim de que uma história possa ser introduzida num filme, ser expandida pela televisão, romances e quadrinhos; seu universo possa ser explorado em games ou experimentado como atração de um parque de diversões. Cada acesso à franquia deve ser autônomo, para que não seja necessário ver o filme para gostar do game e vice-versa. (JENKINS, 2009, p. 135).
}

Robert Pratten é criador do serviço online Transmedia Storyteller, que auxilia nas questões transmídia, sendo um dos primeiros a investir em projetos na área. Para Pratten (2011, p. 1), narrativa transmídia significa: "contar uma história através de vários meios de comunicação e, de preferência, embora nem sempre aconteça, com um grau de participação, interação ou colaboração do público".

Um universo compartilhado, seja ele de filmes, quadrinhos ou games, precisa de fundamentação. Trettin e Schlögl (2014, p. 6) abordam esse tema, afirmando que "para um universo ficcional ser construído, deve-se estabelecer um ambiente onde artistas, outros autores, e fãs possam explorá-lo e experimentá-lo". Também deve ser algo em que obras de diferentes estilos possam ser feitas, criando assim uma espécie de quebracabeças, em que cada obra simboliza uma peça, e assim formando algo como um todo, porque uma única obra não é capaz de abranger todos os elementos, mas ela pode (e deve) ter elementos que indicam pertencer a um universo.

Fontenele (2017) traz um panorama em relação a transmídia no UCM. Ela afirma que, apesar de não usar muitas mídias, os filmes e séries da Marvel Studios aproveitam o que cada uma tem de melhor para oferecer, pois enquanto os filmes 
possuem uma narrativa mais leve, voltada para um público de massa, as séries de televisão e serviço de streaming são focadas para um público específico, no caso o público adulto, pois as narrativas são mais densas e o teor de violência, sexo, palavreado de baixo calão, entre outras coisas são muito maiores.

Da Silva (2015, p. 7) argumenta sobre o efeito que as imagens podem causar por conta da percepção humana:

As imagens apresentam situações e cada situação pode ser alterada através de outras imagens. Elas são ideias de algum objeto ou referente. Com isso, a análise das imagens da mídia corresponde a uma tradução dessas ideias em conceitos que explicam as imagens.

O jornalismo transmídia pode ser definido como uma forma de linguagem que abraça diversos meios, como os audiovisuais, tendo ênfase nos recursos móveis e interação na divulgação, que pode ser feita nas redes sociais: "são adotados recursos audiovisuais, de comunicação móvel e interatividade na divulgação de conteúdos, inclusive da blogosfera e das redes sociais, o que aumenta consideravelmente a circulação de conteúdo" (RENÓ; FLORES, 2018, p. 53).

Canavilhas (2013) propõe alguns conceitos sobre jornalismo transmídia. O primeiro conceito é a interatividade. Ele analisa que a transmídia é a forma de transformar a notícia em cultura, possibilitando uma grande massa a participar ativamente, promovendo a interação sobre determinados temas. O segundo conceito é a hipertextualidade, pois há a possibilidade de se construir conteúdo de forma que não precise ser consumido de forma linear. Por fim, a multimedialidade integrada, que funciona de forma que as diferentes mídias tenham um propósito ao serem usadas.

Santos (2017) trabalha a transmídia dentro do jornalismo de forma que, transportar conteúdos, tendo alterações para se enquadrarem na mídia determinada, não necessariamente caracteriza como uma ação voltada a transmídia, pois esse necessita de coisas novas.

Mesmo com o processo de convergência sendo realizado pelo jornalismo, alguns aspectos transmídia não são recentes, mas sim, atualizações de práticas antigas do jornalismo, como a performance, que é o que atrai o público. Em compensação, nos últimos tempos, determinadas características ganharam seu espaço na área, como o espalhamento e imersão (MARTINS; FECURY, 2016).

Por fim, Cirne (2016, p. 13) afirma que a convergência midiática causa uma mudança não somente nos meios de comunicação, mas também na cultura. Para ela, as 
Jornalismo transmídia e produção de sentidos para o cinema:

o filme Vingadores - guerra infinita nos portais de notícias brasileiros

PAULA, BONA, 2019

práticas transmídia mostram: “[...] uma notável transformação cultural, porque a audiência não só é estimulada a migrar para outras plataformas como sente essa necessidade de buscar novas informações e fazer conexões com conteúdos dispersos". Esta nova forma faz com que a audiência vá deixando de lado o modo antigo de consumo, que pode ser caracterizado como singular.

\section{Metodologia e procedimentos}

Neste trabalho a pesquisa é classificada como descritiva e sua abordagem é a qualitativa. A técnica utilizada é a analise de conteúdo. O universo desta pesquisa é o UCM (Universo Cinematográfico Marvel) e os portais brasileiros de notícia. As amostras são: o filme Vingadores: guerra infinita e os seguintes portais: G1, Globoplay e Omelete. A escolha dos portais se deu pelo fato da variedade de abordagens por eles apontadas de forma não-probabilística por julgamento.

Vingadores: guerra infinita (2018) é o terceiro filme da franquia principal do UCM, Os Vingadores, que também conta com: Os vingadores (2012) e Vingadores: era de Ultron (2015), ambos de Joss Whedon, e Vingadores: ultimato (2019), Anthony e Joe Russo). Os filmes promovem o encontro de vários personagens que foram apresentados e desenvolvidos em filmes solo, além de outros que possuem seus backgrounds apresentados no decorrer das obras.

O G1 é um portal de notícias brasileiro pertencente ao Grupo Globo (GLOBO.COM, 2018), e que engloba o conteúdo jornalístico de várias marcas pertencentes ao grupo, como a Rede Globo, Globo News, Rádios Globo e CBN, jornais O Globo, Extra, revistas Época e Globo Rural, entre outros, todos possuindo atuação no meio digital.

O Globoplay é uma plataforma de streaming pertencente ao Grupo Globo, e que possui site e aplicativo próprios (GLOBO.COM, 2018). A plataforma apresenta conteúdos pagos, como os programas, jornais e novelas, todos na íntegra, além de trechos e reportagens de forma gratuita.

O Omelete é um site de notícias e entretenimento criado pelos críticos de cinema Érico Borgo, Marcelo Forlani e Marcelo Hessel e sendo marca pertencente ao Grupo Omelete\&CO (OMELETECOMPANY.COM, 2018). Inicialmente voltado para os quadrinhos, o portal aumentou a abordagem também para cinema, música, televisão e jogos eletrônicos. 
Jornalismo transmídia e produção de sentidos para o cinema:

o filme Vingadores - guerra infinita nos portais de notícias brasileiros

PAULA, BONA, 2019

Referente à técnica de coleta, foi feita uma busca flutuante nos portais G1, Globoplay e Omelete, nos quais foram selecionadas todas as notícias publicadas entre dezembro de 2017 e setembro de 2018. A coleta deste material foi salva em uma pasta para tratamento posterior. Após a catalogação, as matérias foram lidas para identificar as características da narrativa transmídia nas mesmas, a fim de traçar um perfil de jornalismo transmídia nos portais de notícias do Brasil. Todo o tratamento analítico é feito a partir dos conceitos expostos pelos autores da revisão de literatura. Para a obtenção de resultados referente ao conteúdo publicado nos portais, foi desenvolvido um quadro de análise em que foram atribuídas características transmídia:

Quadro 1: Análise jornalismo transmídia

\begin{tabular}{|l|l|}
\hline \multicolumn{1}{|c|}{ Conceito } & \multicolumn{1}{c|}{ Significado } \\
\hline Expansão & $\begin{array}{l}\text { Amplificação do universo apresentado na obra original. Novas } \\
\text { informaçoses que fazem parte de um todo. }\end{array}$ \\
\hline Imersão & O leitor deve ser instigado a interagir com o conteúdo. \\
\hline Interatividade & Participação ativa do leitor por meio de opiniões e comentários. \\
\hline Hipertextualidade & $\begin{array}{l}\text { Quebra da linearidade. O material pode ser consumido de diversas } \\
\text { maneiras. O uso de hiperlinks cria estruturas hipertextuais } \\
\text { complexas. }\end{array}$ \\
\hline $\begin{array}{l}\text { Multimedialidade } \\
\text { integrada }\end{array}$ & Cada mídia usada deve ter seu propósito. \\
\hline Performance & O que atrai e motiva o público. \\
\hline Espalhamento/Divulgação & Engajamento do público no fluxo de conteúdo \\
\hline
\end{tabular}

Fonte: a partir dos autores da fundamentação teórica: Jenkins (2009); Pratten (2011); Fontenele (2017); Silva (2015); Renó; Flores (2018); Canavilhas (2013); Santos (2017); Martins; Fecury (2016); Cirne (2016).

\section{A Narrativa de Vingadores: Guerra infinita}

Vingadores: guerra infinita tornou-se a quarta maior bilheteria mundial em toda a história do cinema até o ano de 2018 (BOX OFFICE MOJO, 2018). A narrativa é sobre o plano do déspota intergaláctico Thanos (Josh Brolin) na busca pelas seis Joias do Infinito, artefatos místicos que podem controlar e recriar toda a realidade. Homem de Ferro (Robert Downey Jr.), Capitão América (Chris Evans), Thor (Chris Hemsworth), Doutor Estranho (Benedict Cumberbatch), Homem-Aranha (Tom Holland), Viúva Negra (Scarlett Johansson), Hulk (Mark Rufallo), entre outros, se unem aos Guardiões da Galáxia para enfrentar a ameaça imposta pelo Titã Louco, na tentativa de salvar o universo.

Mesmo com as similaridades entre as mídias, uma adaptação cinematográfica de quadrinhos não é simples, pois determinadas técnicas usadas nos filmes simplesmente DOI: http://dx.doi.org/ 10.14393/par-v4n2-2019-48558 Paradoxos, Uberlândia, v. 4, n. 2, p. 5-21, jul./dez. 2019 | 11 
Jornalismo transmídia e produção de sentidos para o cinema:

o filme Vingadores - guerra infinita nos portais de notícias brasileiros

PAULA, BONA, 2019

não funcionam nas HQs: "a transposição de uma história originária de um quadrinho para o meio fílmico não é uma tarefa fácil, visto que o cinema conta com atributos que não são possíveis em histórias em quadrinhos, como o som e a ilusão de movimento real" (DULLIUS, 2015, p. 14). A autora também explica que a passagem de tempo se difere nas duas mídias, de maneira que, nos filmes, os recursos cinematográficos possibilitam passagens de tempo de maneira gráfica, enquanto nos quadrinhos, a sarjeta é usada, sendo aberta para interpretação e imaginação do leitor.

Vingadores: guerra infinita é uma adaptação da Saga do infinito, grande evento dos quadrinhos da Marvel que foi dividido em três partes, Desafio infinito, Guerra infinita e Cruzada infinita. Além das adaptações em questões técnicas, outras precisaram ser feitas, como o corte de personagens, como o Surfista Prateado. Importante na saga dos quadrinhos, nos cinemas os direitos do personagem não pertencem a Marvel Studios, mas sim a Fox. Assim como o Surfista Prateado, outros personagens foram cortados da história no filme, seja por questões de direitos ou decisões criativas. $\mathrm{O}$ espaço para o desenvolvimento também é diferente, pois uma saga dividida em três partes possibilita mais desenvolvimento que um filme de duas horas e meia.

\section{O Portal G1}

O G1 se classifica como um portal de hard news ${ }^{i}$ ou seja, notícias factuais. O perfil de notícias publicadas varia de acordo com o tema em destaque na mídia e na sociedade. Vingadores: guerra infinita foi lançado mundialmente no dia 27 de abril de 2018. O impacto causado pelo filme reflete no portal, pois o pico de notícias relacionadas se deu entre abril e maio. Após o período em que o filme esteve em cartaz nos cinemas, o portal não voltou a falar sobre.

O jornalismo do G1 é produzido para a internet, o que abre portas para a interatividade com o leitor. O atrativo do portal para motivar tal interação é uma seção especial para comentários, aberto para todos que possuam cadastro. A média é de 17 comentários por matéria, sendo um número considerável para fora das redes sociais. $\mathrm{O}$ engajamento do público é parte fundamental para as estratégias de jornalismo online, além da colaboração para a narrativa transmídia, uma vez que o público é parte fundamental, mesmo que a interação não seja uma necessidade. Nas páginas, há a 
Jornalismo transmídia e produção de sentidos para o cinema:

o filme Vingadores - guerra infinita nos portais de notícias brasileiros

PAULA, BONA, 2019

possibilidade de compartilhar o conteúdo nas redes sociais Facebook e Twitter, por meio de dois botões disponíveis, um para cada site.

A hipertextualidade se faz presente como uma característica essencial do conteúdo produzido para a internet. Canavilhas (2013, p. 61) diz que "esta característica permite construir conteúdos navegáveis que podem informar eficazmente os utilizadores, recorrendo para isso a estruturas hipertextuais complexas". Tais estruturas se desprendem da linearidade textual, criando assim um conteúdo que pode ser aproveitado de diversas maneiras. Referente às notícias sobre o filme no portal G1, foram analisadas 20 matérias, sendo 10 antes e 10 após o lançamento, e por meio de vídeos, imagens ou links, foi identificado características hipertextuais. Cada meio usado teve seu propósito. As imagens se dividem entre frames do filme e outras com conteúdos além do que apresentado no texto. As primeiras tratam de apresentar os personagens em questão, além de contextualizar o filme, mostrando a estética usada na produção, instigando ou não o leitor a assisti-lo. As outras tratam de ampliar o assunto, pois abordam a linha do tempo do $U C M$, trazendo para o foco as outras produções da Marvel, na tentativa de explicar o conteúdo em sua totalidade. A característica estética também serve para os vídeos, que em sua maioria são os trailers divulgados. Os links buscam a interação com o público, pois há a opção de participação em enquetes, que, apesar do conteúdo primário se referir a um único filme, elas voltam a trazer a tona todo o universo compartilhado, por meio da seguinte pergunta: “Qual o melhor filme da Marvel?”. Também há um link que redireciona para a explicação da cronologia dos filmes. Os demais links buscam apenas ampliar o conhecimento sobre o filme em questão.

O portal propõe uma imersão dentro da narrativa jornalística de forma que o conteúdo publicado tenha uma linguagem didática e não se contenha apenas em textos. Mesmo após a estreia do filme, é comum ver nas matérias a disponibilidade de algum trailer, levando o leitor a lembrar de sua experiência assistindo a obra. A linguagem usada é simples, e busca explicar os termos que não são do conhecimento da grande massa, criando uma estratégia de público e mercado que abrange um maior número de pessoas por meio de uma forma de linguagem acessível. Essa linguagem auxilia no que se diz respeito ao envolvimento com o universo da franquia, pois o entendimento de termos específicos possibilita o aprofundamento na mitologia desenvolvida e estabelecida pelas 
Jornalismo transmídia e produção de sentidos para o cinema:

o filme Vingadores - guerra infinita nos portais de notícias brasileiros

PAULA, BONA, 2019

produções cinematográficas, criando uma sensação de envolvimento com tal. Estas sensações fazem com que o leitor passe a ser parte do universo estabelecido.

Vingadores: guerra infinita é um filme "incompleto". A sequência direta do longa-metragem chegou em 2019. Devido ao fato do filme ser dividido em dois, a primeira parte termina com um anticlímax, pois os heróis são derrotados pelo vilão Thanos (Josh Brolin). O público leigo pode enxergar como algo ruim, pois os roteiros cinematográficos sempre pendem para o lado do bem. Apesar disso, após os créditos, uma mensagem aparece rapidamente na tela, que diz "Thanos irá retornar". Essa mensagem costuma aparecer após os créditos de todos os filmes da Marvel, identificando o personagem em destaque. Então, apesar de ser intitulado um filme dos Vingadores, Guerra infinita na verdade é um filme sobre Thanos. Esse pequeno detalhe acaba interferindo diretamente na experiência do público.

O portal G1 segue uma lógica parecida, pois o personagem é o mais citado nas matérias, seja diretamente pelo seu nome, ou pelo nome de Josh Brolin, seu intérprete. Apenas quatro matérias não possuíram qualquer ligação ao personagem, e mesmo com o conteúdo sendo produzido especialmente para o mesmo grupo que possivelmente não entendeu a mensagem final do filme, o segmento se torna o mesmo, pois Thanos é o personagem principal da narrativa proposta pelo portal, como nos filmes. Todavia, a sensação de que o personagem é o centro de uma narrativa passa longe de ser algo como nos filmes. O UCM aborda a ameaça do vilão desde o lançamento de Os vingadores (2012, Joss Whedon), deixando claro de que era uma ameaça muito maior do que a recém-enfrentada, Loki. Ele ainda apareceu em Guardiões da galáxia (2014, James Gunn), e era tido como o grande vilão do segundo filme dos Vingadores, que acabou sendo o androide Ultron. Thanos foi desenvolvido em pistas colocadas nos filmes durante seis anos para que o público criasse a empatia necessária e estivesse preparado para o que viria pela frente. Tal expansão narrativa só se tornou possível pelo planejamento de universo compartilhado criado pela Marvel, dando a possibilidade de exploração por parte dos fãs, mas que pode ficar oculto para quem não acompanha todos os filmes com afinco. No G1, apesar da presença constante, Thanos está mais escondido, e apenas o tamanho de sua ameaça é enfatizado. 
Jornalismo transmídia e produção de sentidos para o cinema:

o filme Vingadores - guerra infinita nos portais de notícias brasileiros

PAULA, BONA, 2019

\section{O Portal Globoplay}

O Globoplay é um portal voltado para o streaming. O conteúdo publicado se refere ao material produzido para a televisão na Rede Globo e sucursais estaduais. As produções não são todas voltadas ao jornalismo, mas também ao entretenimento, como as séries e novelas do canal, que estão disponíveis para assinantes. A forma em que o portal trabalha converge para o uso da internet como uma espécie de ferramenta de expansão televisiva. Em vez de tentar substituir a televisão, o portal busca trabalhar em sintonia, disponibilizando o conteúdo para o público que possivelmente não teve a oportunidade de acompanhar na mídia original. Essa prática altera o modo com que o conteúdo é produzido, uma vez que também é pensado para a internet.

O conteúdo, uma vez disponibilizado na internet, muda a forma de pensar do espectador. Antes, caso não estivesse em casa na hora do programa, não poderia assistilo, mas atualmente, acessando o serviço, há a opção de ver o conteúdo no momento que quiser. Tal prática, na visão de Cirne (2016), já faz parte da cultura, uma vez que o público é estimulado a migrar para novas plataformas. Esse estímulo também se deve aos recursos móveis, como smartphones e tablets. O Globoplay possui aplicativos para essas plataformas, dando a atenção devida, conforme explicam Renó e Flores (2018).

Diferentemente do portal G1, no Globoplay, o filme não teve o mesmo impacto. Antes da estreia foram encontrados apenas dois vídeos referentes ao tema, e nenhum deles possui caráter jornalístico. Após a estreia o número aumenta para dez, sendo oito voltados à informação, um com um paralelo com esporte e um voltado ao entretenimento.

As pautas do portal são mais variadas, abordando desde a narrativa do filme, até questões comerciais. Os recursos audiovisuais são usados de forma que transmita a mesma tensão necessária que o filme quer que o espectador sinta, parte disso se deve a montagens com cenas dos trailers e o forte uso do tema do filme, composto por Alan Silvestri. Ou seja, o uso de imagens e do tema do filme contribui de forma eficiente para a produção de sentidos, uma vez que se encaixam com perfeição tanto na narrativa do filme, quanto na narrativa jornalística. Vingadores: guerra infinita possui uma trama de fácil entendimento. O vilão Thanos quer a posse das Joias do Infinito para por em prática seu plano. Cabe aos Vingadores e aos Guardiões da Galáxia defender o universo. Dentro da narrativa jornalística, a explicação da trama do longa-metragem é tão simples 
Jornalismo transmídia e produção de sentidos para o cinema:

o filme Vingadores - guerra infinita nos portais de notícias brasileiros

PAULA, BONA, 2019

quanto. As matérias abordam de forma breve e objetiva. Mais uma vez o vilão é o personagem mais citado, tendo aparecido em nove dos doze vídeos analisados, e sua ameaça fica mais evidente do que no portal G1, muito devido ao já citado tema composto por Silvestri, que transmite a imponência do personagem.

Referente à interação, o fluxo de comentários do Globoplay é extremamente baixo. Devido ao fato de se utilizar primariamente dos recursos audiovisuais, a seção destinada para comentários fica "escondida" em relação ao G1. Dentro do conteúdo analisado, em apenas um vídeo foi encontrado comentário, sendo este único. Os demais não possuem qualquer interação por parte do público. Uma explicação plausível para isso se deve ao fato do portal ter sua parcela de público voltada aos recursos móveis. Uma pessoa que assiste o conteúdo dentro do ônibus dificilmente se prestará a interagir, visto que aproveita do seu tempo livre para consumir um conteúdo já produzido. O conteúdo relacionado não segue a temática em questão, e sim alguns padrões, como em que região o conteúdo foi produzido e outros conteúdos do mesmo programa, porém, nunca referente ao tema.

\section{O Portal Omelete}

O Omelete é um portal voltado ao público geek. O conteúdo publicado é exclusivamente sobre filmes, quadrinhos, jogos eletrônicos, etc. Por ser dedicado a um público seleto, pautas consideradas frias para o jornalismo hard news do G1 são quentes para o portal, visto que os fãs buscam por informações vindas de portais especializados. Isso fica evidente já na busca por conteúdo, uma vez que o fluxo de matérias relacionadas a Vingadores: guerra infinita se manteve meses após o lançamento do longa-metragem. O portal foi originalmente fundado como uma plataforma online, então não precisou passar por uma transição midiática. Porém, variados recursos disponíveis para o meio digital foram anexados ao conteúdo, como um canal no YouTube, com conteúdo exclusivo todos os dias.

Referente à interação, nas 20 matérias analisadas, a média foi de 105 comentários por notícia. Porém, essa interatividade é bem maleável, pois os números variam bastante. A notícia falando sobre as primeiras impressões da crítica sobre o filme atingiu o impressionante número de 1.293 comentários, enquanto outras, referentes aos 
Jornalismo transmídia e produção de sentidos para o cinema:

o filme Vingadores - guerra infinita nos portais de notícias brasileiros

PAULA, BONA, 2019

bastidores do filme sequer atingiram dez comentários. Parte se deve ao hype criado pela comunidade de fãs, uma vez que a Marvel vendeu a produção como a culminação de um universo construído por dez anos. Essa interação ainda pode ser expandida para outros meios, pois o portal disponibiliza quatro botões para compartilhamento no Facebook, Twitter, E-mail e WhatsApp.

O portal não apela para recursos visuais. São poucas as imagens disponíveis, e quando há, geralmente são apenas frames do filme. A característica mais usada para expandir a narrativa são os links. Todas as matérias possuem links para conteúdos relacionados, seja do filme ou do universo compartilhado construído pela Marvel. Esta prática possibilita uma maior exploração pelos fãs. Desconsiderando vídeos e imagens, a forma que o Omelete aproveita os links é muito similar a do portal G1, com a diferença de que não há enquetes, mas sim, matérias muito específicas sobre o filme, como a explicação de determinada cena. Este conteúdo não teria espaço nos outros portais, a menos que fosse durante o período em que o filme estivesse em cartaz.

O portal possui uma linguagem prévia de abordagem. Por ser destinado a um público específico, não há a necessidade de se produzir um conteúdo muito didático. A prova disso são os textos curtos, sem muitas explicações técnicas. O portal também pouco fala sobre a narrativa do filme. Prova disso é que o vilão principal, Thanos, é citado poucas vezes, enquanto os diretores do filme, Joe e Anthony Russo aparecem em dez matérias. Isso provoca uma sensação totalmente diferente no leitor.

O portal busca expandir o que há por trás das câmeras, e deixa o $U C M$ em si um pouco de lado. Thanos, o mais citado nos primeiros portais, aqui é substituído pelos diretores do filme, os irmãos Russo, deixando clara esta abordagem diferente que o portal busca.

\section{Discussão dos resultados}

Referente ao G1, podemos considerar que a narrativa transmídia se faz presente como parte ativa de uma produção voltada para a internet. O portal busca criar um conteúdo para todos os grupos, seja o hardcore, ou o mais casual. O conteúdo do portal não se agarra totalmente no universo dos filmes, trazendo a parte informativa voltada a questões técnicas e mercantis, e também um material dedicado a desenvolver e destrinchar a parte narrativa das produções da Marvel, porém, esta expansão de 
Jornalismo transmídia e produção de sentidos para o cinema:

o filme Vingadores - guerra infinita nos portais de notícias brasileiros

PAULA, BONA, 2019

conteúdo forma a ligação entre o portal e a nave-mãe. O portal busca a interação com o público a fim de estabelecer uma relação próxima entre o produtor e o consumidor, e por meio de características hipertextuais, estimula a navegação, a quebra da linearidade, além de ampliar a percepção referente ao assunto em questão.

Considerando a informação como o universo, o conteúdo do Globoplay propõe uma visão um pouco diferente do jornalismo transmídia. Os vídeos ainda seguem a narrativa da televisão, porém são fragmentados para que possam ser consumidos rapidamente na internet de forma individual. Apesar disso, ainda pertencem a uma narrativa muito maior, mas que não se torna necessário o acompanhamento para o entendimento do conteúdo em questão. O conteúdo aborda um pouco mais a narrativa do filme, a expectativa e aceitação por parte dos fãs, podendo em momentos servir de propaganda para a produção da Marvel. O "clima" apresentado nos vídeos segue de perto a grandiosidade proposta pelo longa-metragem, e a força do vilão, transportando a estética visual da obra, dando a sensação de que faz parte da narrativa do filme.

Quanto ao Omelete, a consideração que fica é de que o portal busca se distanciar da narrativa padrão imposta pelos portais de notícias gerais. Por ser destinado a um público específico, o portal tem mais liberdade na criação de conteúdo, e a produção de sentido não se torna uma característica tão relevante quanto nos outros portais, uma vez que o fã já tem sua percepção sobre a obra muito bem construída.

No intuito de observar melhor o resultado das análises, o quadro apresenta um resumo da pesquisa realizada:

Quadro 2: Resultados das análises

\begin{tabular}{|l|c|c|c|}
\hline & G1 & Globoplay & Omelete \\
\hline Linguagem didática & $\mathrm{X}$ & $\mathrm{X}$ & $\mathrm{X}$ \\
\hline Linguagem direcionada & & & $\mathrm{X}$ \\
\hline Uso de links & $\mathrm{X}$ & $\mathrm{X}$ & $\mathrm{X}$ \\
\hline Uso alto de recursos audiovisuais & $\mathrm{X}$ & $\mathrm{X}$ & \\
\hline Fluxo de conteúdo relacionado ainda ativo & & $\mathrm{X}$ \\
\hline Interação baixa & $\mathrm{X}$ & & \\
\hline Interação moderada & & $\mathrm{X}$ & \\
\hline Interação alta & $\mathrm{X}$ & $\mathrm{X}$ & \\
\hline Auxilia na construção estética do filme & & $\mathrm{X}$ & \\
\hline Conteúdo pensado para recursos móveis & & & \\
\hline
\end{tabular}

Fonte: Dados da pesquisa. 
Jornalismo transmídia e produção de sentidos para o cinema:

o filme Vingadores - guerra infinita nos portais de notícias brasileiros

PAULA, BONA, 2019

Conforme apresentado na revisão de literatura, a interação por parte do público não é obrigatória para a construção da narrativa transmídia. Apesar de muitas vezes ser parte presente do material de um determinado portal, a prática não se sustenta como uma característica. Prova disso é a análise de cada portal. Eles apresentaram diferentes níveis de interação. Dentre todos os portais analisados, o Omelete foi o que apresentou a maior participação ativa dos leitores.

\section{Considerações finais}

A narrativa transmídia propõe a expansão de um determinado universo por meio de uma grande narrativa fragmentada em pequenas partes que funcionam isoladamente. No jornalismo, o universo poderia ser caracterizado como a informação, e a expansão dela possibilitam novas visões para um tema. Então, jornalismo transmídia é a junção de informação e tecnologia, proporcionando uma expansão narrativa que tem o intuito de ampliar o campo de entendimento do consumidor.

As franquias de cinema caminham em direção da transmídia, visto que, após o sucesso do $U C M$, diversos grandes estúdios buscam criar seus próprios universos compartilhados, adequando os filmes para esta narrativa. $\mathrm{O}$ tom experimental que a Marvel adotou em seus primeiros filmes, denominados de Fase 1, criou uma espécie de cartilha de expansão de universo, que estes outros estúdios buscam emular e adequar para as suas propostas. A Marvel criou uma nova maneira de fazer cinema, e Vingadores: guerra infinita é uma prova, visto que sua alta bilheteria se deve ao hype criado nos últimos anos, desde a estreia do primeiro filme do estúdio, Homem de Ferro (2008).

A pesquisa buscou analisar a narrativa transmídia jornalística do filme Vingadores: guerra infinita nos portais de notícias do Brasil. Os resultados são positivos e demonstram que cada portal dá novos sentidos para o filme, cada um com suas peculiaridades. Nos portais G1 e Omelete, a característica transmídia mais forte é o uso de links para expansão de conteúdo. Pelo fato do conteúdo produzido ser destinado à internet, não há a necessidade de adaptações, pois o material é devidamente pensado para as mídias. Esse não é o caso do Globoplay. O portal fragmenta o conteúdo produzido para a televisão, a fim de entrar nas características da internet. Porém, a forma de consumir esse conteúdo se difere muito da maneira tradicional, devido à atenção dada aos recursos 
Jornalismo transmídia e produção de sentidos para o cinema:

o filme Vingadores - guerra infinita nos portais de notícias brasileiros

PAULA, BONA, 2019

móveis, o que mexe diretamente na cultura, conforme explica Cirne (2016). Além disso, o material do Globoplay aproveita o uso do audiovisual, emulando o clima proposto pelo longa-metragem, por meio de cenas e da trilha sonora composta por Alan Silvestri, o que mostra o tamanho que o filme se propõe a ter. Tal prática estimula o hype, fazendo com que o conteúdo passe a ser parte da experiência cinematográfica.

O conteúdo do G1 segue uma forma muito parecida com o do $U C M$, porém, dentro da narrativa jornalística. Thanos (Josh Brolin) pode ser considerado como o personagem principal dentro dessa narrativa, uma vez que é o mais citado. O portal busca emular o conteúdo dos filmes dentro de uma maneira que se enquadre para todos os públicos, seja para quem já viu ou não o filme. Ele busca expandir o universo de $O s$ Vingadores para fora do cinema por meio de uma narrativa transmídia, anexando a estética visual da obra com a parte informativa.

Quanto ao Globoplay, a narrativa é diferente do portal G1. As pautas são mais abrangentes, abordando desde a história do filme até a reação dos grupos de fãs. $\mathrm{O}$ caráter informativo/didático também se faz presente, pois parte do público é o mesmo do outro portal, já que ambos pertencem ao mesmo grupo, e uma parcela do conteúdo do Globoplay também é vinculado ao G1.

Enquanto os outros portais buscam criar um laço entre o leitor e o universo dos filmes, o Omelete trata de abordar os bastidores, fazendo com que quem esteja na frente do computador se sinta parte da equipe de produção, uma vez que, como já citado, os recursos visuais são discretos, e a estética do filme não fica clara para a percepção de quem esteja consumindo o conteúdo.

\section{Referências}

BOX OFFICE MOJO. Disponível em: <https://bit.ly/2qfWDsd>. Acesso em: 19 out. 2018.

CANAVILHAS, João. Jornalismo Transmídia: um desafio ao velho ecossistema midiático. Bogotá: Editorial Universidad del Rosário, 2013.

CIRNE, Lívia. De uma para muitas... mídias: uma abordagem da transmidiação no telejornalismo. ÂNCORA-Revista Latino-americana de Jornalismo, v. 3, n. 2, 2016. https://doi.org/10.21204/2359-375x/ancora.v3n2p194-208

DA SILVA, Rodrigo Carvalho. Produção de sentido nas imagens do cinema. Temática, v. 8, n. 9, 2015. Disponível em: <https://bit.ly/2qfXxF4>. Acesso em: 29 out. 2018. 
Jornalismo transmídia e produção de sentidos para o cinema:

o filme Vingadores - guerra infinita nos portais de notícias brasileiros

PAULA, BONA, 2019

DOS SANTOS, Marcio C. Existe Jornalismo Transmídia? Considerações Sobre o Reuso de Conceitos. São Carlos: Revista GEMInIS, v. 8, n. 3, p. 136-149, 2017. Disponível em: <https://bit.ly/2QGwJdm>. Acesso em: 09 set. 2018.

DULLIUS, Amanda Amaral. A franquia Os Vingadores como parte da narrativa transmídia do universo cinematográfico Marvel: um estudo de caso. 2015. Disponível em: < https://bit.ly/2Da0obd>. Acesso em: 19 out. 2018.

FONTENELE, Amanda V. Narrativa Transmídia: Um Passeio pelo Universo Marvel Cinematográfico. Fortaleza: Universidade Federal do Ceará, 2017. Disponível em <https://bit.ly/2PLEq0u>. Acesso em: 05 set. 2018.

GLOBO.COM. Disponível em: <https://bit.ly/2ODQkZn>. Acesso em: 02 dez 2018.

IMDB. Disponível em: 〈https://imdb.to/2I1E96W〉. Acesso em: 02 dez 2018.

JENKINS, Henry. Cultura da convergência. 2. ed. São Paulo: Aleph, 2009.

MARTINS, Elaide; FECURY, Isabelle. Entre o portal e o telejornal: aspectos da narrativa transmídia no jornalismo do grupo Record. In: CONGRESSO INTERNACIONAL DE CIBERJORNALISMO. 2016. Disponível em: 〈https://bit.ly/2D6L8fV〉. Acesso em: 21 ago. 2018.

OMELETE\&CO. Disponível em: <https://bit.ly/2ALg4Os>. Acesso em: 02 dez. 2018

PRATTEN, Robert. Getting started in transmedia storytelling: a pratical guide for beginners. Londres, 2011. Disponível em: 〈https://bit.ly/2Dbl2sb〉. Acesso em: 04 set. 2018.

RENÓ, Denis; FLORES, Jesús M. Periodismo Transmedia. Nueva edición actualizada. Aveiro: Ria Editoral, 2018.

SCOLARI, Carlos A. Transmedia Storytelling: Implicit Consumers, Narrative Worlds, and Branding in Contemporary Media Production. Catalunya, 2009. Disponível em: <https://bit.ly/2D9hQxn>. Acesso em: 21 ago. 2018.

TRETTIN, Diego; SCHLÖGL, Larissa. A narrativa transmidiática dos vingadores da Marvel Comics: Análise dos filmes homem de ferro e homem de ferro 2. Razón y Palabra, v. 18, n. $88,2014$.

Data Recebimento: 08/05/2019

Data Aprovação: 10/2019

\footnotetext{
${ }^{1}$ Em inglês, tem o sentido de notícia importante. Designa o relato objetivo de fatos e acontecimentos relevantes para a vida política, econômica e cotidiana. Disponível em: <https://www1.folha.uol.com.br/folha/circulo/manual_producao_h.htm> Acesso em: 02 dez. 2018.
} 